\title{
Nonlinear Response of Strong Nonlinear System Arisen in Polymer Cushion
}

\author{
Jun Wang, ${ }^{1,2}$ Li-xin Lu, ${ }^{1,2}$ Huan-xin Jiang, ${ }^{1,2}$ and Yong $\mathrm{Zhu}^{3}$ \\ ${ }^{1}$ Key Laboratory of Food Packaging Techniques and Safety of China National Packaging Corporation, \\ Wuxi, Jiangsu 214122, China \\ ${ }^{2}$ Department of Packaging Engineering, Jiangnan University, Wuxi, Jiangsu 214122, China \\ ${ }^{3}$ Packaging Engineering Research Institute, Jinan University, Zhuhai, Guandong 519070, China \\ Correspondence should be addressed to Jun Wang; wangj_1982@jiangnan.edu.cn
}

Received 14 December 2012; Revised 30 December 2012; Accepted 30 December 2012

Academic Editor: Lan Xu

Copyright (c) 2013 Jun Wang et al. This is an open access article distributed under the Creative Commons Attribution License, which permits unrestricted use, distribution, and reproduction in any medium, provided the original work is properly cited.

A dynamic model is proposed for a polymer foam-based nonlinear cushioning system. An accurate analytical solution for the nonlinear free vibration of the system is derived by applying He's variational iteration method, and conditions for resonance are obtained, which should be avoided in the cushioning design.

\section{Introduction}

Packaged products can be potentially damaged by dropping. In order to prevent any damage, a product and a cushioning packaging are always included in a packaging system $[1,2]$, and it is very important to investigate the condition for resonance. However, the oscillation in the packaging system is of inherent nonlinearity [3-5], and it remains a problem to obtain the resonance condition for nonlinear packaging system. Polymer foams, especially EPS (expanded polystyrene), are widely used for cushion or protective packaging, and the governing equations can be expressed as

$$
\begin{gathered}
m \ddot{x}+\beta_{3} \operatorname{th}\left(\beta_{1} x\right)+\beta_{4} \tan \left(\beta_{2} x\right) \\
+\beta_{5} \tan ^{3}\left(\beta_{2} x\right)=0, \\
x(0)=0, \\
\dot{x}(0)=\sqrt{2 g h} .
\end{gathered}
$$

Here, the coefficient $m$ denotes the mass of the packaged product, while $\beta_{i}$ denote, respectively, the characteristic constants of polymer foams which could be obtained by compression test, and $h$ is the dropping height.
By introducing these parameters: $T_{0}=\sqrt{m / \beta_{1} \beta_{3}}, L=$ $1 / \beta_{1}$ and let $X=x / L, T=t / T_{0}, \lambda_{1}=\beta_{2} / \beta_{1}, \lambda_{2}=\beta_{4} / \beta_{3}$, and $\lambda_{3}=\beta_{5} / \beta_{3}$, (1) can be written in the following forms

$$
\begin{gathered}
\ddot{X}+\operatorname{th} X+\lambda_{2} \tan \left(\lambda_{1} X\right) \\
+\lambda_{3} \tan ^{3}\left(\lambda_{1} X\right)=0, \\
X(0)=0, \\
\dot{X}(0)=V=\frac{T_{0}}{L} \sqrt{2 g h}=\sqrt{\frac{2 \beta_{1} m g h}{\beta_{3}} .}
\end{gathered}
$$

By using Taylor series for $\sin X$ and $\tan X$, (2) can be equivalently written as

$$
\begin{gathered}
\ddot{X}+\omega_{01}^{2} X+\left(-\frac{1}{3}+\lambda_{3} \lambda_{1}^{3}+\frac{1}{3} \lambda_{2} \lambda_{1}^{3}\right) X^{3} \\
+\left(\frac{2}{15}+\frac{2}{15} \lambda_{2} \lambda_{1}^{5}+\lambda_{3} \lambda_{1}^{5}\right) X^{5}+\frac{11}{15} \lambda_{3} \lambda_{1}^{7} X^{7}=0, \\
X(0)=0, \\
\dot{X}(0)=V=\frac{T_{0}}{L} \sqrt{2 g h}=\sqrt{\frac{2 \beta_{1} m g h}{\beta_{3}}},
\end{gathered}
$$


where

$$
\omega_{01}=\sqrt{1+\lambda_{1} \lambda_{2}}
$$

\section{Variational Iteration Method}

The variational iteration method [6-13] has been widely applied in solving many different kinds of nonlinear equations [6-16], and is especially effective in solving nonlinear vibration problems with approximations [17-20]. Applying the variational iteration method [6-13], the following iteration formulae can be constructed:

$$
\begin{aligned}
& X_{1}=X_{0}+\frac{1}{\omega_{01}} \\
& \times \int_{0}^{t} \sin \omega_{01}(s-t)\left\{\ddot{X}_{0}+\omega_{01}^{2} X_{0}\right. \\
&+\left(-\frac{1}{3}+\lambda_{3} \lambda_{1}^{3}+\frac{1}{3} \lambda_{2} \lambda_{1}^{3}\right) X_{0}^{3} \\
&+\left(\frac{2}{15}+\frac{2}{15} \lambda_{2} \lambda_{1}^{5}+\lambda_{3} \lambda_{1}^{5}\right) X_{0}^{5} \\
&\left.+\frac{11}{15} \lambda_{3} \lambda_{1}^{7} X_{0}^{7}\right\} d s .
\end{aligned}
$$

Beginning with the initial solutions,

$$
X_{0}=A \sin (\Omega t) .
$$

We have

$$
\begin{aligned}
X_{1}=A & \sin (\Omega t)-\frac{1}{\omega_{01}\left(\Omega^{2}-\omega_{01}^{2}\right)} \\
& \times\left(a A+\frac{3}{4} b A^{3}+\frac{5}{256} c A^{5}-\frac{637}{1024} d A^{7}\right) \\
( & \left.\Omega \sin \left(\omega_{01} t\right)+\omega_{01} \sin (\Omega t)\right) \\
& -\frac{1}{4 \omega_{01}\left(9 \Omega^{2}-\omega_{01}^{2}\right)}\left(b A^{3}+\frac{5}{64} c A^{5}-\frac{189}{256} d A^{7}\right) \\
( & \left.3 \Omega \sin \left(\omega_{01} t\right)+\omega_{01} \sin (3 \Omega t)\right) \\
& +\frac{1}{16 \omega_{01}\left(25 \Omega^{2}-\omega_{01}^{2}\right)}\left(c A^{5}+\frac{7}{4} d A^{7}\right) \\
( & \left.5 \Omega \sin \left(\omega_{01} t\right)+\omega_{01} \sin (5 \Omega t)\right) \\
& -\frac{d A^{7}}{64 \omega_{01}\left(49 \Omega^{2}-\omega_{01}^{2}\right)} \\
& \times\left(7 \Omega \sin \left(\omega_{01} t\right)+\omega_{01} \sin (7 \Omega t)\right),
\end{aligned}
$$

where

$$
\begin{gathered}
a=1+\lambda_{1} \lambda_{2}, \\
b=-\frac{1}{3}+\frac{1}{3} \lambda_{2} \lambda_{1}^{3}+\lambda_{3} \lambda_{1}^{3}, \\
c=\frac{2}{15}+\frac{2}{15} \lambda_{2} \lambda_{1}^{5}+\lambda_{3} \lambda_{1}^{5}, \\
d=\frac{11}{15} \lambda_{3} \lambda_{1}^{7} .
\end{gathered}
$$

\section{Resonance}

The resonance can be expected when one of the following conditions is met:

$$
\begin{aligned}
\Omega & =\omega_{01}, \\
\Omega & =\frac{1}{3} \omega_{01}, \\
\Omega & =\frac{1}{5} \omega_{01}, \\
\Omega & =\frac{1}{7} \omega_{01} .
\end{aligned}
$$

These conditions should be avoided during the cushioning packaging design procedure.

\section{Conclusion}

The conditions for resonance, which should be avoided in the cushioning packaging design procedure, can be easily obtained using the variational iteration method.

\section{Acknowledgments}

This work was supported by the National Natural Science Foundation of China (Grant no.: 51205167), the Research Fund of Young Scholars for the Doctoral Program of Higher Education of China (Grant no.: 20120093120014), and the Fundamental Research Funds for the Central Universities (Grant no.: JUSRP51302A).

\section{References}

[1] R. E. Newton, Fragility Assessment Theory and Practice, Monterey Research Laboratory, Monterey, Calif, USA, 1968.

[2] G. J. Burgess, "Product fragility and damage boundary theory," Packaging Technology and Science, vol. 1, no. 1, pp. 5-10, 1988.

[3] J. Wang and Z. W. Wang, "Damage boundary surface of a tangent nonlinear packaging system with critical component," Journal of Vibration and Shock, vol. 27, no. 2, pp. 166-167, 2008.

[4] J. Wang, Z. W. Wang, L. X. Lu, Y. Zhu, and Y. G. Wang, “Threedimensional shock spectrum of critical component for nonlinear packaging system," Shock and Vibration, vol. 18, no. 3, pp. 437-445, 2011.

[5] J. Wang, J. H. Jiang, L. X. Lu, and Z. W. Wang, "Dropping damage evaluation for a tangent nonlinear system with a critical component," Computers and Mathematics with Applications, vol. 61, no. 8, pp. 1979-1982, 2011. 
[6] J.-H. He, "Variational iteration method-a kind of non-linear analytical technique: some examples," International Journal of Non-Linear Mechanics, vol. 34, no. 4, pp. 699-708, 1999.

[7] J.-H. He, "Variational iteration method-Some recent results and new interpretations," Journal of Computational and Applied Mathematics, vol. 207, no. 1, pp. 3-17, 2007.

[8] J.-H. He and X. H. Wu, "Variational iteration method: new development and applications," Computers and Mathematics with Applications, vol. 54, no. 7-8, pp. 881-894, 2007.

[9] J.-H. He, "Some asymptotic methods for strongly nonlinear equations," International Journal of Modern Physics B, vol. 20, no. 10, pp. 1141-1199, 2006.

[10] G.-C. Wu, "Laplace transform overcoming principal drawbacks in application of the variational iteration method to fractional heat equations," Thermal Science, vol. 6, no. 4, pp. 1257-1261, 2012.

[11] J.-H. He, "Asymptotic methods for solitary solutions and compactons," Abstract and Applied Analysis, vol. 2012, Article ID 916793, 130 pages, 2012.

[12] J.-H. He, "An elementary introduction to recently developed asymptotic methods and nanomechanics in textile engineering," International Journal of Modern Physics B, vol. 22, no. 21, pp. 3487-3578, 2008.

[13] J.-H. He, "Notes on the optimal variational iteration method," Applied Mathematics Letters, vol. 25, no. 10, pp. 1579-1581, 2012.

[14] J. Singh, P. K. Gupta, and K. Nath Rai, "Variational iteration method to solve moving boundary problem with temperature dependent physical properties," Thermal Science, vol. 15, supplement 2, pp. S229-S239, 2011.

[15] J. Wang, Y. Khan, R. H. Yang, L. X. Lu, Z. W. Wang, and N. Faraz, "A mathematical modelling of inner-resonance of tangent nonlinear cushioning packaging system with critical components," Mathematical and Computer Modelling, vol. 54, no. 11-12, pp. 2573-2576, 2011.

[16] S. T. Mohyud-Din, M. A. Noor, and K. I. Noor, "Variational iteration method for Burgers' and coupled Burgers' equations using He's polynomials," Zeitschrift für Naturforschung Section A, vol. 65 , no. 4, pp. 263-267, 2010.

[17] L. N. Zhang and J.-H. He, "Resonance in Sirospun yarn spinning using a variational iteration method," Computers and Mathematics with Applications, vol. 54, no. 7-8, pp. 1064-1066, 2007.

[18] L. Xu, "Dynamics of two-strand yarn spinning in forced vibration," Nonlinear Analysis, Theory, Methods and Applications, vol. 71, no. 12, pp. e827-e829, 2009.

[19] D. H. Shou, "He's variational iteration method for two-strand yarn spinning," Nonlinear Analysis: Theory, Methods and Applications, vol. 71, no. 12, pp. e830-e833, 2009.

[20] R. H. Yang and S. Y. Wang, "Resonance in a rotor-spun composite yarn spinning process obtained using the variational iteration method," Computers and Mathematics with Applications, vol. 58, no. 11-12, pp. 2486-2488, 2009. 


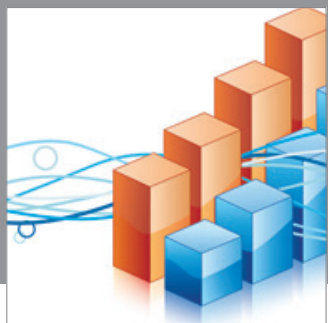

Advances in

Operations Research

mansans

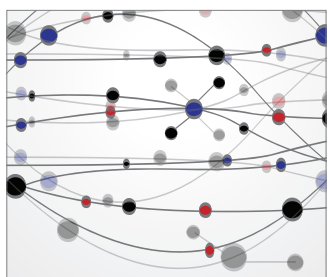

The Scientific World Journal
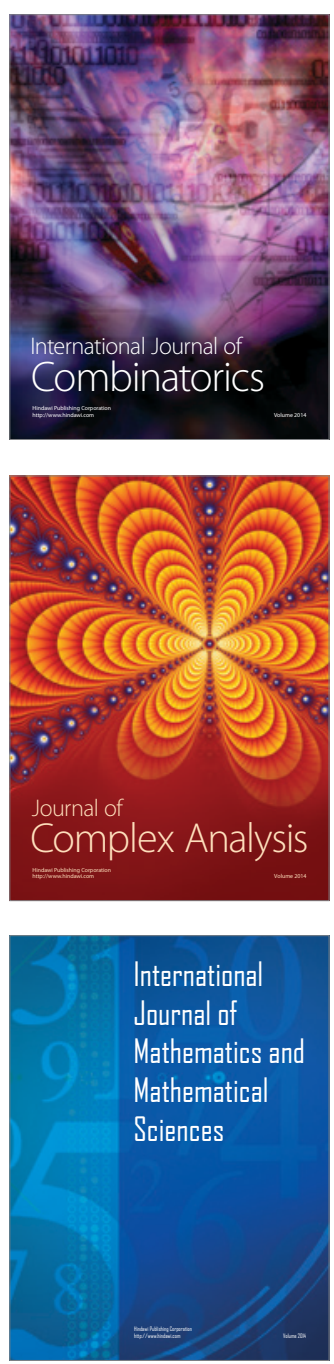
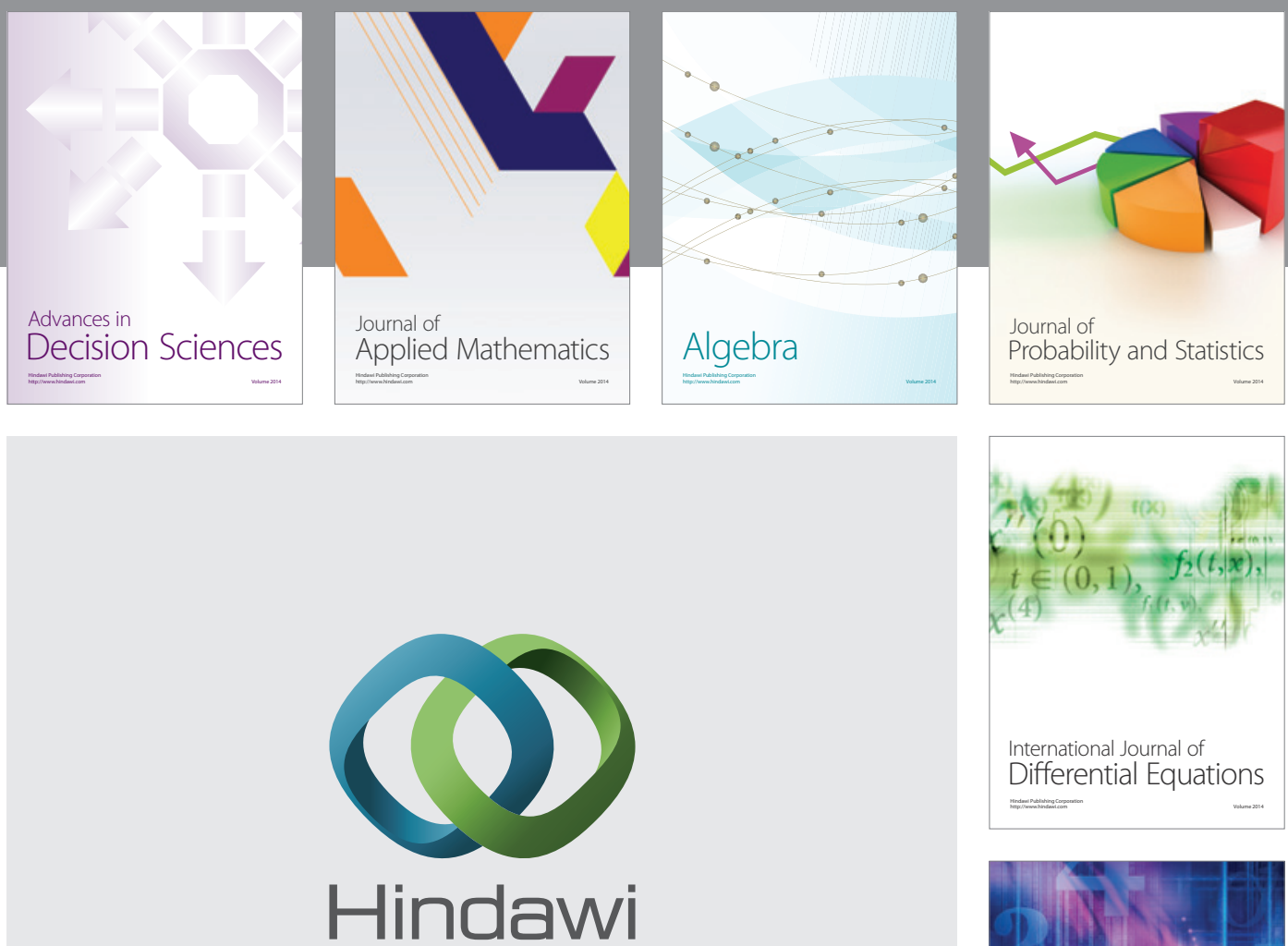

Submit your manuscripts at http://www.hindawi.com
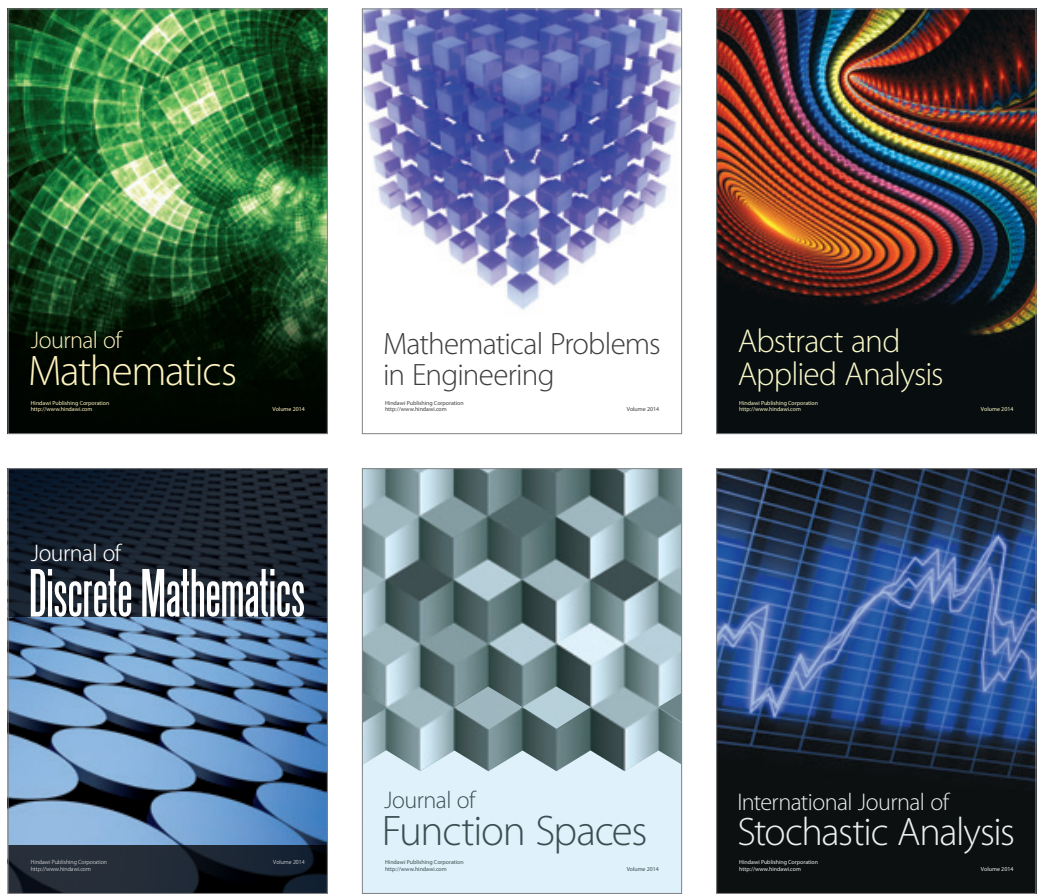

Journal of

Function Spaces

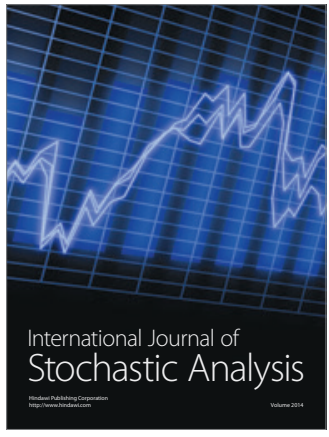

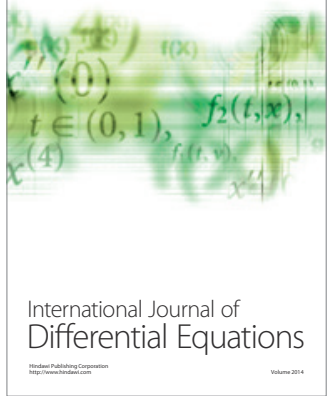
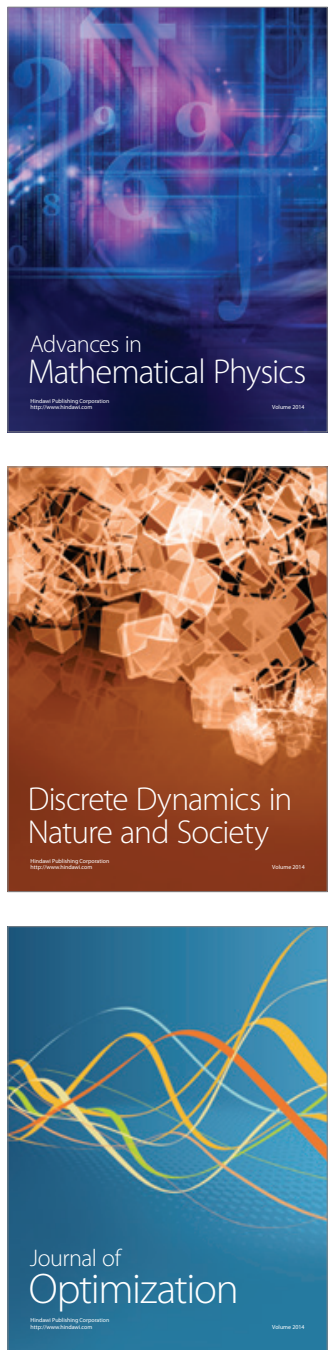